\title{
HIPNOSIS, NLP DAN MOTIVASI UNTUK MENINGKATKAN KUALITAS SDM GURU DI SEKOLAH BHAKTI PRIMA PAMULANG
}

\author{
Arif Surahman ${ }^{1}$, Juwita Ramadani Fitria ${ }^{2}$, Rissa Hanny ${ }^{3}$, Ade Rachmawan ${ }^{4}$, \\ Achmad Agus Yasin Fadli ${ }^{5}$ \\ 1,2,3,4,5) Program Studi Manajemen, Fakultas Ekonomi, Universitas Pamulang \\ email :dosen01176@unpam.ac.id
}

\begin{abstract}
Abstrak
Sebagai makhluk sosial manusia membutuhkan bantuan orang lain. Manusia akan selalu berusaha untuk memenuhi kebutuhannya dan memerlukan motivasi atau dorongan dari orang lain untuk mencapai apa yang menjadi tujuan hidupnya. Pemberian motivasi dengan tepat akan dapat menimbulkan semangat, gairah dan keikhlasan kerja dalam diri seseorang. Meningkatnya kegairahan dan kemauan untuk bekerja dengan sukarela tersebut akan menghasilkan pekerjaan yang lebih baik, sehingga akan meningkatkan produktivitas kerja. Sedangkan seseorang yang mempunyai motivasi kerja rendah, mereka akan bekerja seenaknya dan tidak berusaha untuk mendapatkan hasil yang maksimal. Motivasi seorang karyawan untuk bekerja biasanya merupakan hal yang rumit, karena motivasi melibatkan faktor-faktor individual dan faktor-faktor organisasional. Pekerja yang kompeten dapat berkontribusi besar untuk mempercepat pertumbuhan perusahaan, sehingga keberadaannya sangatlah penting. Maka dari itu, mempertahankan karyawan berkompeten adalah salah satu tantangan terbesar bagi instansi. Terlebih, pada masa pandemi seperti saat ini. Kondisi perusahaan yang mungkin menjadi tidak stabil akan memicu kekhawatiran dari tiap pekerja. Pimpinan perusahaan harus memikirkan secara khusus bagaimana caranya mempertahankan karyawan terbaik perusahaan untuk tetap tergabung dalam organisasi dengan segala pertimbangan di masa pandemi ini. Untuk itu diperlukan Pelatihan yang bekerja sama dari berbagai keahliah Dosen, diantaranya SDM. Pada kesempatan ini kami melatih para karyawan untuk bagaiman supaya tetap termotivasi dengan menggunakan metode Hipnosis dan NLP dan meningkatkan Motivasi.
\end{abstract}

Kata Kunci : Hipnosis, NLP, Motivasi.

\begin{abstract}
As a social creature, human needs other people help. Humans will always try to fulfill their needs and also they need motivation or a push from others to achieve their live purposes. The right dose of motivations can cause high spirit, pationate and sincere work ethics inside someone. The increase of pations and the will to work sincerely will result high productivity, and because of that will increase better work productivity. While contrary with that, someone who has low work motivations, they will work as they wishes and not trying to achieve maximum effort in their work. Work motivations of an employee usually involved with something that is complicated, because motivation contains individual factors and oganizational factors. Maintaining a competent worker is one of a big challange to a company. Furthermore, in times of pandemic like today, companies can be unstable and can caused concerns among employees. Company leaders has to specificly think about on how to maintain their best employee to still be in the organizations with all the considerations in times of pandemics like today. Because of that, employee training is very needed especially that come from lecturer that has multiple backgrouds, among them is human resource lecturer. In this opportunity we are training employees on how to keep motivated by using Hypnosis and NLP to increase productivity.
\end{abstract}

Keywords : Hypnosis, NLP, Motivations

\section{PENDAHULUAN}

Sebagai makhluk sosial manusia membutuhkan bantuan orang lain. Manusia akan selalu berusaha untuk memenuhi kebutuhannya dan memerlukan motivasi atau dorongan dari orang lain untuk mencapai apa yang menjadi tujuan hidupnya.

Pimpinan organisasi atau perusahaan merupakan orang yang bekerja dengan bantuan dari para bawahannya, yaitu karyawan. Oleh karena itu, sudah menjadi kewajiban dari seorang pimpinan untuk mengusahakan agar para karyawan berprestasi. Kemampuan bawahan untuk dapat berprestasi disebabkan dengan adanya dorongan atau motivasi. 
Pemberian motivasi dengan tepat akan dapat menimbulkan semangat, gairah dan keikhlasan kerja dalam diri seseorang. Meningkatnya kegairahan dan kemauan untuk bekerja dengan sukarela tersebut akan menghasilkan pekerjaan yang lebih baik, sehingga akan meningkatkan produktivitas kerja. Sedangkan seseorang yang mempunyai motivasi kerja rendah, mereka akan bekerja seenaknya dan tidak berusaha untuk mendapatkan hasil yang maksimal.

Motivasi seorang karyawan untuk bekerja biasanya merupakan hal yang rumit, karena motivasi melibatkan faktor-faktor individual dan faktor-faktor organisasional. Yang tergolong pada faktor individual yang memberikan pengaruh terhadap motivasi kerja adalah tujuan, sikap dan kemampuan. Sedangkan yang tergolong pada faktor yang berasal dari organisasi yang memberikan pengaruh terhadap motivasi kerja adalah gaji, keamanan pekerjaan dan hubungan sesama pekerja.

Pekerja yang kompeten dapat berkontribusi besar untuk mempercepat pertumbuhan perusahaan, sehingga keberadaannya sangatlah penting. Maka dari itu, mempertahankan karyawan berkompeten adalah salah satu tantangan terbesar bagi instansi.

Terlebih, pada masa pandemi seperti saat ini. Kondisi perusahaan yang mungkin menjadi tidak stabil akan memicu kekhawatiran dari tiap pekerja. Pimpinan perusahaan harus memikirkan secara khusus bagaimana caranya mempertahankan karyawan terbaik perusahaan untuk tetap tergabung dalam organisasi dengan segala pertimbangan di masa pandemi ini

Untuk itu diperlukan Pelatihan yang bekerja sama dari berbagai keahliah Dosen, diantaranya SDM. Dalam kesempatan ini kami dari keahlian SDM akan memaparkan bagaimana cara untuk tetap termotivasi dalam bekerja ditengah pandemic seperti saat ini dengan menggunakan metode Hipnosis dan NLP.

Adapun tahapan metode Pengabdian Kepada Masyarakat (PKM) dimulai dari pertemuan dengan Pengurus Sekolah Bhakti Prima lalu pengabdi membuat pencatatan atau mendata permintaan dari Sekolah Bhakti Prima dalam hal ini akan memberikan pelatihan dalam bidang apa. Pengabdi melakukan konsultasi dengan konsultan sekolah Selanjutnya data dibawa musyawarah ke pertemuan internal Pengabdi dan diputuskan untuk mengadakan pelatihan perihal pelatihan Hipnosis, NLP, dan Motivasi kerja Guru. Agar kedepannya kerjasama bisa berjalan dengan baik dan berkesinambungan.

Dalam Pelatihan ini akan di kenalkan pengertian Hipnosis dan NLP. Walupun para peserta sudah tidak asing lagi karena mereka sudah terbiasa mendapatkan pelatihan, sudah barang tentu mereka sudah tidak asing lagi apa itu Hipnosis dan NLP. Ada banyak materi motivasi dapat diberikan dengan hipnosis dan NLP, diantaranya adalah sugestibilitas dan rileksasi.

Setelah pengabdian ini dilaksanakan maka tahapan berikutnya pengabdi akan melakukan pendataan dari hasil pelatihan terutaman mengenai Tanya jawab perihal bagaimana cara melakukan releksasi saat stres kerja melanda, bagaimana cara memotivasi diri dan orang lain, dan untuk terus berfikir positif kapanpun dan dimanapun.

Maka Dengan ini pentingnya pelatihan hypnosis, NLP dan Motivasi untuk guru dan kepala sekolah pada sekolah Bhakti Prima Pamulang, sebagai wujud Tri Darma Perguruan Tinggi, Fakultas Ekonomi S1 UNPAM, maka akan menyelenggarakan Pengabdian Kepada Masyarakat (PKM) dengan judul "Hipnosis, NLP dan Motivasi Untuk Meningkatkan Kualitas SDM Guru di Sekolah Bhakti Prima Pamulang"

\section{METODE}

Langkah yang dilaksanakan dalam kegiatan ini merupakan langkah awal dari Pengabdian Kepada Masyarakat dimulai dari observasi langsung ke sekolah Bhakti Prima Pamulang, dan mencari informasi yang dibutuhkan pada saat pelaksanaan PKM. Langkah selanjutnya menetapkan tujuan PKM, kemudian mengidentifikasikan permasalahan tersebut dalam bentuk proposal PKM. Langkah terakhir adalah melakukan kegiatan PKM, serta membuat hasil kegiatan PKM. Metode kegiatan yang digunakan adalah melalui kunjungan langsung ke sekolah Bhakti Prima Pamulang, dengan memberikan seminar, pelatihan dan pendampingan terhadap guru dan Kepala sekolah.

\section{Khalayak Sasaran}

Sasaran dalam Pengabdian Kepada Masyarakat ( PKM ) ini adalah Guru dan Kepala Sekolah Bhakti Prima Pamulang.

\section{HASIL DAN PEMBAHASAN}

Dengan disetujuinya proposal pengabdian masyarakat yang diajukan dosen Universitas Pamulang di Sekolah Bhakti Prima Pamulang kami menyampaikan kepada Rektor Universitas 
Pamulang untuk menindaklanjuti acara tersebut sampai menunggu waktu pelaksanaan yang ditentukan oleh Sekolah Bhakti Prima Pamulang. Setelah melakukan koordinasi maka disepakati bersama acara dilaksanakan selama 3 hari sesuai ketentuan dalam pelaksanaan Pengabdian Kepada Masyarakat ( PKM) yaitu pada tanggal 01 sampai dengan tanggal 03 Nopember 2020 bertempat ruang kelas Sekolah Bhakti Prima Pamulang.

Setelah proposal disetujui dari pihak Sekolah Bhakti Prima Pamulang dan LPPM, tim dosen Pengabdian Kepada Masyarakat Universitas Pamulang melakukan pertemuan dan diskusi dengan kepala sekolah, serta survei terkait tempat yang akan digunakan untuk kegiatan PKM yaitu seminar dan pelatihan kepada kepala Sekolah Bhakti Prima Pamulang. Kegiatan ini dilakukan pada tanggal 01 Desember 2020. Kegiatan berlangsung dari pukul 09.00-15.00 WIB.

\section{Simpulan}

Berdasarkan pelaksanaan kegiatan Pengabdian Kepada Masyarakat yang dilaksanakan di sekolah Bhakti Prima Pamulang yang berlangsung pada tanggal 01 sampai dengan tanggal 03 Desember 2020 dapat disimpulkan bahwa :

1) Kehadiran Pengabdian Kepada Masyarakat dari Unpam dalam membantu guru dan kepala sekolah sangat dirasakan manfaatnya oleh guru dan kepala sekolah Bhakti Prima Pamulang, sehingga di harapkan akan meningkat kualitas guru di sekolah tersebut.

2) Guru dan Kepala sekolah meninta diadakan kembali pelatihan.

\section{Saran}

Guna tercapai tujuan dari pengarahan, seminar, penyuluhan atau pelatihan dan pendampingan sekolah Bhakti Prima ada beberapa saran yang perlu diperbaiki, yakni :

1) Komunikasi

Komunikasi disini sangatlah penting karena keberhasilan dalam berkomunikasi antara pengarahan, seminar, penyuluhan atau pelatihan dan pendampingan guru, maka akan memudahkan program-program pengarahan, penyuluhan atau pelatihan dan pendampingan dapat berjalan dengan baik.

2) Pendidikan Harapan para guru mampu melanjutkan Pendidikan ke jenjang lebih tinggi/

3) Kualitas Berharap kualitas guru semakin meningkat dari semua aspek

\section{UCAPAN TERIMA KASIH}

Kami ucapkan terimakasih yang sebesar-besarnya kepada LPPM UNPAM, karena tanpa pembiayaan yang telah diberikan pengabdian yang kami lakukan mungkin tidak dapat dilakukan. Selain itu, kami juga mengucapkan terimakasih kepada pihak-pihak yang telah bersedia untuk mengikuti acara pengabdian yang telah kami lakukan.

\section{DAFTAR PUSTAKA}

Ahmadi. (1988). Panduan Pengajar Buku Ketrampilan Menulis. Jakarta: PPLPTK.

Anthony, M. (2020, Mei 27). https://www.sehatq.com. Diambil kembali dari https://www.sehatq.com/artikel/apa-itu-hipnosis-dan-bagaimana-cara-kerjanya:

https://www.sehatq.com/artikel/apa-itu-hipnosis-dan-bagaimana-cara-kerjanya

Hendrawaty. Dkk. (2006). Bisnis dan Manajemen. . Jurnal Ilmiah Berkala Empat Bulanan, 1411 9366 Volume 2 No. 3.

Mondy, R. W. (2008). Manajemen Sumber Daya Manusia. Terj. Edisi kesepuluh jilid I. Jakarta: Erlangga.

Nurindra, Y. (2013, Maret 26). https://www.hipnotis.net. Diambil kembali dari https://www.hipnotis.net/apakah-manfaat-nlp-bagi-seorang-hipnoterapis/: https://www.hipnotis.net/apakah-manfaat-nlp-bagi-seorang-hipnoterapis/

Siswanto. (2005). Pengantar Manajemen. Jakarta: Bumi Aksara.

Teguh, I. M. (2013). Seminar Pendidikan. Singaraja: Ganesha Press.

Tunggal, A. W. (2012). Manajemen: Suatu Pengantar. Jakarta: Rineka Cipta. 